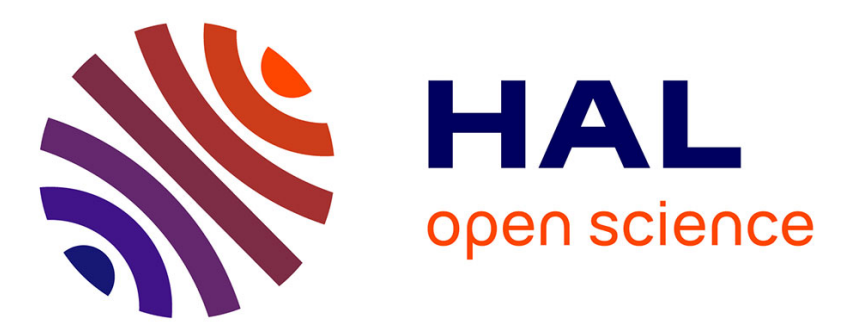

\title{
Selection of effective cocrystals former for dissolution rate improvement of active pharmaceutical ingredients based on lipoaffinity index
}

\author{
Piotr Cysewski, Maciej Przybylek
}

\section{- To cite this version:}

Piotr Cysewski, Maciej Przybylek. Selection of effective cocrystals former for dissolution rate improvement of active pharmaceutical ingredients based on lipoaffinity index. European Journal of Pharmaceutical Sciences, 2017, 107, pp.87-96. 10.1016/j.ejps.2017.07.004 . hal-01773096

\section{HAL Id: hal-01773096 \\ https://hal.science/hal-01773096}

Submitted on 29 Apr 2018

HAL is a multi-disciplinary open access archive for the deposit and dissemination of scientific research documents, whether they are published or not. The documents may come from teaching and research institutions in France or abroad, or from public or private research centers.
L'archive ouverte pluridisciplinaire HAL, est destinée au dépôt et à la diffusion de documents scientifiques de niveau recherche, publiés ou non, émanant des établissements d'enseignement et de recherche français ou étrangers, des laboratoires publics ou privés. 


\section{Accepted Manuscript}

Selection of effective cocrystals former for dissolution rate improvement of active pharmaceutical ingredients based on lipoaffinity index

Piotr Cysewski, Maciej Przybyłek

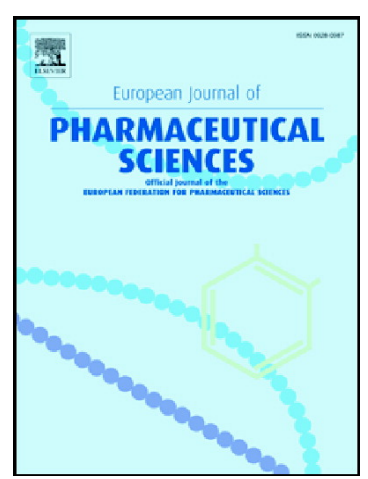

PII: S0928-0987(17)30403-7

DOI: doi: 10.1016/j.ejps.2017.07.004

Reference: PHASCI 4127

To appear in: European Journal of Pharmaceutical Sciences

Received date: $\quad 11$ April 2017

Revised date: $\quad 6$ June 2017

Accepted date: $\quad 3$ July 2017

Please cite this article as: Piotr Cysewski, Maciej Przybyłek, Selection of effective cocrystals former for dissolution rate improvement of active pharmaceutical ingredients based on lipoaffinity index, European Journal of Pharmaceutical Sciences (2017), doi: 10.1016/j.ejps.2017.07.004

This is a PDF file of an unedited manuscript that has been accepted for publication. As a service to our customers we are providing this early version of the manuscript. The manuscript will undergo copyediting, typesetting, and review of the resulting proof before it is published in its final form. Please note that during the production process errors may be discovered which could affect the content, and all legal disclaimers that apply to the journal pertain. 


\title{
Selection of effective cocrystals former for dissolution rate improvement of active pharmaceutical ingredients based on lipoaffinity index
}

\author{
Piotr Cysewski and Maciej Przybyłek \\ Chair and Department of Physical Chemistry, Pharmacy Faculty, Collegium Medicum of Bydgoszcz, \\ Nicolaus Copernicus University in Toruń, Kurpińskiego 5, 85-950 Bydgoszcz, Poland, \\ piotr.cysewski@cm.umk.pl
}

"corresponding author

\begin{abstract}
New theoretical screening procedure was proposed for appropriate selection of potential cocrystal formers possessing the ability of enhancing dissolution rates of drugs. The procedure relies on the training set comprising 102 positive and 17 negative cases of cocrystals found in the literature. Despite the fact that the only available data were of qualitative character, performed statistical analysis using binary classification allowed to formulate quantitative criterions. Among considered 3679 molecular descriptors the relative value of lipoaffinity index, expressed as the difference between values calculated for active compound and excipient, has been found as the most appropriate measure suited for discrimination of positive and negative cases. Assuming $5 \%$ precision, the applied classification criterion led to inclusion of $70 \%$ positive cases in the final prediction. Since lipoaffinity index is a molecular descriptor computed using only 2D information about a chemical structure, its estimation is straightforward and computationally inexpensive. The inclusion of an additional criterion quantifying the cocrystallization probability leads to the following conjunction criterions $\mathrm{H}_{\text {mix }}<-0.18$ and $\Delta \mathrm{LA}>3.61$, allowing for identification of dissolution rate enhancers. The screening procedure was applied for finding the most promising coformers of such drugs as lloperidone, Ritonavir, Carbamazepine and Enthenzamide.
\end{abstract}

\section{Keywords}

dissolution rate, pharmaceutical cocrystals, excipients screening, molecular descriptors, hydrophilicity

\section{Chemical compounds studied in this article}

lloperidone (PubChem CID: 71360); Ritonavir (PubChem CID: 392622); Carbamazepine (PubChem CID: 2554); Ethenzamide (PubChem CID: 3282); Acetylsalicylic acid (PubChem CID: 2244); Piroxicam (PubChem CID: 54676228); Indomethacin (PubChem CID: 3715); Ketoprofen (PubChem CID: 3825); Paracetamol (PubChem CID: 1983); Sulfamethazine (PubChem CID: 5327)

\section{Introduction}

During last half century enormous in vitro and in vivo attempts have been made to model drug dissolution behavior (Pestieau and Evrard, 2017). The dissolution profile measurement of active pharmaceutical ingredient (API) is the most fundamental method for assessment of drug absorption. Although the bioavailability is a complex issue and not straightforwardly correlated with in vitro results (Lu et al., 2011) this approach is still valuable and effective at the pre-formulation stage of solid phase dosage form development. There are several basic techniques of dissolution profile determination but about $70 \%$ of results available on FDA (Food and Drug Administration) (FDA, 2017) dissolution rates database were obtained using paddle method (Shohin et al., 2016). Other approaches were applied to a lesser extent, including the basket method, flow-through cell measurements or reciprocating cylinder approaches (Shohin et al., 2016). Since tablet is the most frequently studied dosage form, many methods of crystal engineering have been applied for dissolution rate (DSR) enhancement rather than thermodynamic solubility. Improvement of dissolution profiles can be obtained by particle size reduction techniques (Choi and Park, 2017; Dizaj et al., 2015; Khadka et al., 2014; Sironi et al., 2017), crystal morphology/polymorphism modifications (Amodwala et al., 2017; Jain et al., 2017; Keraliya et al., 2010; Maghsoodi, 2015) or multicomponent 
crystals synthesis (Ross et al., 2016; Schultheiss and Newman, 2009; Yadav et al., 2009). The latter approach including bi-component cocrystallization deserves particular attention due to the variety of cocrystal preparation methods such as solvent evaporation techniques (Bag et al., 2011; Bag and Reddy, 2012; Cysewski et al., 2016; Przybyłek et al., 2016a, 2016b), antisolvent crystallization (Chun et al., 2014; Lee et al., 2015; Wang et al., 2013), mechanochemical co-grinding (Hasa et al., 2015; Karki et al., 2007; Li et al., 2016; Tröbs and Emmerling, 2014) or slurry methods (Apshingekar et al., 2017; Kojima et al., 2010; Takata et al., 2008). Furthermore, the variety of cocrystals formers applicable for pharmaceutical formulations offers fine tuning of physicochemical properties of new multicomponent solids (Good and Rodríguez-Hornedo, 2009). Nutraceuticals (Sekhon, 2012) is an exemplary class of non-toxic chemicals embracing among others phenolic acids, flavonoids, vitamins and saccharides (Aitipamula et al., 2012; Bethune et al., 2011; Sekhon, 2012; Sinha et al., 2015). There are also many potential candidates for cocrystallization with other chemicals found for example on EAFUS (Everything Added to Food in the United States) and GRAS (Generally Regarded as Safe) lists provided by FDA.

There are several interesting examples of improving rate of drug dissolution throughout cocrystal synthesis. For instance, according to Sanphui et al. (2011) dissolution rates of Curcumin cocrystals with Resorcinol and Pyrogallol are respectively 5 and 12 times higher than pure Curcumin. Another example is anticoagulant Apixaban, which exhibits poor aqueous solubility and bioavailability. Chen et al. (2016) have found that this can be easily overcome via cocrystallization with oxalic acid. According to this study, the bioavailability of Apixaban, if dosed to beagle dogs, is about two times higher when the oxalic acid cocrystal was applied. Many more examples can be found in the literature, which were systematically collected for the purpose of this study. Extensive survey allowed for gathering of cases of pharmaceutical cocrystals, for which the dissolution rates have been studied experimentally. Unfortunately, these data are methodologically quite inconsistent what prevents from collecting of the actual values of DSR enhancements. However, available information allows for discrimination of excipients between DRS enhancers or reducers. Indeed, interesting examples of new forms of drugs with improved dissolution profile can be found in the case of such antibiotics as Clarithromycin and Prulifloxacin (Nanjwade et al., 2011; Rajbhar et al., 2016a, 2016b). Besides, such neuropsychiatric drugs as Carbamazepine, Agomelatine, Domperidone, lloperidone and Paliperidone were also studied (Hoffman and Lindeman, 2012; Lahamage et al., 2016; Moradiya et al., 2014; Mounika et al., 2016; Shayanfar et al., 2013; Yamashita and Sun, 2016; Yan et al., 2012; Zhang et al., 2014, 2013). Additionally, solid dispersions of analgesics and nonsteroidal anti-inflammatory drugs such as Acetylsalicylic acid, Aceclofenac, Acemetacin, Ethenzamide, Celecoxib, Etodolac, Indomethacin, Ketoprofen, Lornoxicam, Meloxicam, Piroxicam and Paracetamol were extensively studied (Aitipamula et al., 2012; Brown, 2012; Cheney et al., 2011; Gadade et al., 2017; Haeria and Isriany, 2015; Hiendrawan et al., 2016; Jung et al., 2010; Moradiya et al., 2016; Patel et al., 2014; Remenar et al., 2007; Sanphui et al., 2014; Siswandi et al., 2015; Sohrab et al., 2015; Zahid, 2014). Many examples of cocrystals dissolution rates can be found also in case of antiinfective agents (Chadha et al., 2012; Cherukuvada et al., 2011; Childs, 2009; Gao et al., 2011; Goud et al., 2014; Gujar et al., 2013; Imchalee and Charoenchaitrakool, 2015; Jung et al., 2015; Kumar, 2014; Manin et al., 2015; Nalte et al., 2015; Paun et al., 2013; Remenar et al., 2003; Sateesh Babu et al., 2013; Sekhon, 2012; Serrano et al., 2016; Shah et al., 2004). This wide class of APIs includes such drugs as Adefovir, Dipivoxil, Arbidol, Efavirenz, Itraconazole, Nevirapine, Nitrofurantoin, Ritonavir, Sulfamethazine, Sulfamethoxazole, Tinidazole, Voriconazole, Isoniazid, Metronidazole and Sulfacetamide. Furthermore DSR enhancement was also studied for Exemestane and Megestrol acetate acting as antineoplastics (Shiraki et al., 2008). Such interest was also focused on some cardiovascular agents including Cilnidipine, Felodipine, Irbesartan, Telmisartan, Apixaban, Ezetimibe, Fenofibrate, Olanzapine, Sildenafil, Tadalafil (Arafa et al., 2016; Chadha et al., 2014; Chen et al., 2016; Info, 2013; Khor et al., 2016; Nijhawan et al., 2015; Punita et al., 2016; Renkoğlu et al., 2015; Shewale et al., 2015; Shiraki et al., 2008; Sugandha et al., 2014; Vinesha et al., 2013; Žegarac et al., 2014). There are also single studies devoted to antiallergics as Fexofenadine (Mounika et al., 2015), antidiabetic agents as Gliclazide (Prawiro et al., 2016), AMG 517, Danazol, Famotidine (Bak et al., 2008; Childs et al., 2013; Shi et al., 2013), sodium channel blockers as 4-(4- 
Fluorophenoxy)benzaldehyde semicarbazone (McNamara et al., 2006) and chelating agents as Deferiprone (Zhang et al., 2016). In addition to the aforementioned typical APIs, several drug-like compounds and nutraceuticals such as benzamide (Grossjohann et al., 2012), pterostilbene (Bethune et al., 2011), curcumin (Sanphui et al., 2011), baicalein (Huang et al., 2014), quercetin (Smith et al., 2011) and epigallocatechin-3-gallate (Smith et al., 2013) were taken into account by some investigators.

As it was reported in our previous works (Cysewski, 2017; Przybyłek et al., 2017), in silico methods can be quite successful in cocrystal screening and predicting cocrystal solubility advantage. Particularly, it was shown (Przybyłek et al., 2017) that compounds containing polar $\mathrm{OH}$ and $\mathrm{COOH}$ groups are excellent methylxanthines solubility enhancers. Solubility increase in the presence of hydrophilic compounds is consistent with many experimental data (Brough et al., 2015; Savjani et al., 2012; Thiry et al., 2017b). It is understandable that hydrophilic excipients will also improve the dissolution profile. However, there are no reports documenting rational criterions for selection of coformers suitable for efficient dissolution rate enhancements. This paper filling this gap offers new theoretical screening protocol relying on the two criterions narrowing the list of potential coformers, for which both probability of cocrystallization and DRS enhancement is high enough. This strategy can be helpful by suggesting appropriate compounds for the development of new solid forms of APIs with improved bioavailability.

\section{Methods}

\subsection{Training set of API cocrystals}

Based on literature survey the collection of active pharmaceutical ingredients cocrystalized with different excipients was prepared. Since dissolution rates have been experimentally studied using diverse measurements techniques, the quantified database cannot be built. Instead, a separation of cases into positive and negative sub-classes was conducted. The latter group comprised cases for which no sensible improvement of solubility kinetics was observed. On the contrary, the positive subset collected cocrystals, for which significant gain was observed in terms of dissolution rate improvements with respect of the pure drug. These data were used as training sets for performed chemometric analysis and comprised 102 positive and 17 negative systems. Detailed characteristics of all cocrystals used in this study can be found in supporting materials as collected in Table S1.

\subsection{Cocrystallization probability assessments}

The probability of formation of a homogeneous binary solid by two given components was estimated based on mixing paradigm (Klamt, 2012) relying on the assumption that intermolecular interactions directing formation of the intermolecular complexes in the solid state can be reliably estimated by components affinity expressed in terms of enthalpic contribution to mixing under hypothetical super-cooled conditions at ambient temperature. The formal definition is as follows

$$
\Delta H_{\text {mix }}=x_{1} H_{12}^{1}+x_{2} H_{12}^{2}-\left(x_{1} H_{1}^{1}+x_{2} H_{2}^{2}\right)
$$

where $\mathrm{x}$ denotes molar fraction, superscripts represent solvent types and subscripts denote solutes. Thus, excess enthalpy can be obtained by subtracting enthalpies values characterizing pure components from the sum of molar enthalpies of components in the mixture. From the practical point of view three calculations are indispensable, namely two for each of pure components and one for mixture formed at given stoichiometry. This method requires the estimation of so called $\sigma$ profiles defined in the framework of COSMO-RS (Conductor like Screening Model for Real Solvents) approach (Klamt, 1995) implemented in COSMOtherm software (COSMOlogic GmbH \& Co. KG, 2016). For this purpose the geometries of the most significant conformations of any considered compound were fully optimized both in the gas and condensed phases using BP-RI/TZVP scheme and finally $\sigma$ profiles generation on BP-RI/TZVPD level. All these calculations were performed with an aid of TURBOMOLE V7.0 (TURBOMOLE-GmbH, 2015) interfaced with TmoleX 4.2. Prior to this stage conformational analysis of all compounds was performed using OpenBable (O'Boyle et al., 2011) capabilities. The whole procedure was applied both to drugs and potential excipients. The 
parametrization enabling for final $\mathrm{H}_{\text {mix }}$ computations is defined in BP_TZVPD_FINE_C30_1601.ctd set (COSMOlogic GmbH \& Co. KG, 2016) and stands for the current state of art of these kinds of computations.

Only such compounds were selected as potential coformers, which have the chance of being applied in real manufacturing of pharmaceutical cocrystals. Hence, the first choice of such coformers are collections termed EAFUS and GRAS published by FDA. Additionally, the set was also augmented by some neutracuetics including phenolic acids, their esters and some hydroxyl benzoic acids marked as non-toxic. The coformers list used for screening purposes comprised finally nine aliphatic dicarboxylic acids, 37 phenolic acids, 97 esters, 68 aldehydes, 89 ketones, 20 amines, 134 alcohols, 103 heterocyclic compounds, 56 sulfur containing species, 34 ethers and additionally 550 other compounds of great variety of structural diversities. In total 1194 compounds were used as potential cocrystal formers. In order to distinguish salts from neutral cocrystals, the criterion of probability of proton transfer can be utilized, which is typically indicated by differences in components pKa values. Hence, it is assumed that proton transfer between interacting conformers occurs if $\Delta \mathrm{pKa}=\mathrm{pKb}$ pKa>2.7. Since there are no available experimental data of pKa for all considered compounds, predicted values were used instead. For this purpose the free online tool provided by ChemAxon was utilized (http://epoch.uky.edu/ace/public/pKa.jsp) (Szegezdi and Csizmadia, 2007).

\subsection{Molecular descriptors computation}

Descriptors were computed using online facilities of ChemDes Version 1.0 (Dong et al., 2015). The following five sets of molecular descriptors were included, namely Chemopy (Cao et al., 2013), Bluedesc, CDKit, and PaDel (Yap, 2011). All 2D-type molecular parameters were obtained based on information coded in smiles strings. Since there are some inconsistencies in smiles generation depending on the algorithms used, here for keeping coherency, one source of these data was used for all compounds. Features of the OpenBable (O'Boyle et al., 2011) program were used for generation of smiles strings using sdf files with previously optimized geometries that were used during $\mathrm{H}_{\text {mix }}$ computations. Also for computations of 3D descriptors the same geometry files were applied. Since the training set comprising experimental data was limited, the potential bias of cases collection was alleviated by randomization. Hence, the binary classification was performed 20 times for every molecule descriptors set after random selection of $50 \%$ of data. Then the collected false positive FP\% and true positives TP\% percentages were averaged. Also the associated standard deviation values were computed. It was assumed that this approach at least partly compensates shortage of experimental data used for finding molecular descriptors adequate for distinguishing positive and negative cases. The results of this screening was documented in supporting materials (see Table S2) by collecting molecular descriptors which include at least $50 \%$ of true positive cases assuming $95 \%$ confidence, what means inclusion of at most $5 \%$ false positive cases in prediction.

\section{Results and Discussion}

In the first stage of this study many various molecular descriptors were generated in terms of their applicability for dissolution rate improvement assessment. Then, the virtual cocrystal screening was performed for four drugs, namely lloperidone, Ritonavir, Carbamazepine, Ethenzamide. All these compounds belonging to the II class of Biopharmaceutics Classification System (high permeability and low solubility) have been extensively studied in terms of bioavailability and dissolution profile improvement (Aitipamula et al., 2012; Danjo, K., Nataka, T. \& Otsuka, 1997; Foglio Bonda et al., 2016; Gadade et al., 2017; Ibrahim et al., 2010; Ige et al., 2015; Jitkar et al., 2016; Kojo et al., 2017; Miwa et al., 2016; Remenar et al., 2003; Six et al., 2004; Thiry et al., 2017a, 2016). It is understandable that not all pharmaceutically accepted excipients are miscible in the solid phase with a particular API in the form of a cocrystal. Therefore, an additional step characterizing probability of cocrystallization was performed.

\subsection{Selection of appropriate molecular descriptor}

The chemometric domain (Xue and Bajorath, 2000) matured to offer a variety of molecular descriptors (Mannhold, 2007; Todeschini and Consonni, 2010), which can be used for extracting 
precise information about miscellaneous physicochemical properties of chemical compounds. The vast number and a great diversity of molecular parameters enables for comprehensive characteristics of different contributions to the studied phenomena. Here, the differentiation between excipients being able to enhance the dissolution rates and those not possessing this property was the objective of the performed screening. Although the explicit target function was not defined, as it is the case for typical QSPR studies, it was still possible to achieve a quantification using a binary classification approach (Powers, 2011; Vihinen, 2012). This methods relies on the statistical analysis of the percentages of true positive (TP), false positive (FP), true negative (TN) and false negative (FN) cases varying as a function of a given threshold parameter. Here, such threshold value was addressed to all of considered molecular descriptor differences between API and coformer and was set as to not exceed 5\% uncertainty (amount of FP\%) as a typical and reasonable statistical uncertainty criterion. The final criterion applied for selection of the most useful molecular parameters was related the highest possible value of TP associated with an acceptable level of FP inaccuracy. The search for the highest percentage of positive cases included in the model with simultaneous preserving of at most $5 \%$ of FP was extended over all 3679 molecular descriptors used for classification. During this stage only the compounds included in the training set as positive and negative subsets were used. As a result, the final set of molecular descriptors was restricted to those offering efficiency higher than $65 \%$. This was graphically documented in Fig.1. Interestingly, the best descriptive potential was found to be addressed to lipoaffinity index (LA) (R Liu et al., 2001; Ruifeng Liu et al., 2001), for which the inclusion of as many as $70 \%$ true positive cases was possible. This descriptor quantifying lipoaffinity is not bundled with hydroaffinity since it represents summing over atomic E-state indices other than nitrogen and oxygen centers. Thus, the main contributions come from carbon atoms and atoms of low hydrogen bonding capacity such as halogen ones. Also those atoms, which are characterized by high polarizability, as for example $\mathrm{P}$ or $\mathrm{S}$, have significant contributions to LA. The definition of lipoaffinity index uses weighting (Gramatica et al., 2000; Hall and Kier, 1995; Ruifeng Liu et al., 2001) estimated based on linear regressions. The most important fact of LA is that it is defined on the basis of topological E-state indices, which do not require molecular 3-D information. Hence, no significant computations are really necessary for estimating values of this molecular descriptor. The second parameter of potential usefulness is MaxAasC. It is also related to atomic E-state characteristics but includes only the maximal value for carbon atom in each compound and so it encompasses similar information of molecules as LA. Finally, the third parameter of potential discriminating power is simply LogP in variant computations protocols. This is in accord with chemical intuition and pharmaceutical drug delivery strategies (Brough et al., 2015; Ghanbarzadeh et al., 2016; Kalepu and Nekkanti, 2015; Maggi et al., 2013; Sareen et al., 2012; Savjani et al., 2012; Serajuddin, 1999; Sruti et al., 2013) that differences in polarities between drug and excipient is a main driving force toward dissolution. Many examples of such cases can be found in the literature, including cocrystals but also other types of solid mixtures such as inclusion complexes with cyclodextrins (Dua et al., 2011; M Badr-Eldin et al., 2013; Thiry et al., 2017a, 2017b) and dispersions with soluble polymers (Brough et al., 2015; Choi and Park, 2017; Ibrahim et al., 2010; Maggi et al., 2013; Six et al., 2004; Thiry et al., 2017a). Noteworthy, Guha et al., (2011), found that APIs can be classified in terms of their kinetic solubility values using different hydrophilicity indices. Hence, all three molecular descriptors identified during screening procedure are related to differences in the polarity of cocrystals components. Indeed, the positive values of all three measures considered here suggest that the higher difference the higher chance of dissolution rate enhancement. For example, the threshold value of $\Delta \mathrm{LA}$ associated with $5 \%$ confidence is equal to 3.61 . It is worth mentioning that despite similarities in both definition and meaning, the selected parameters are almost not correlated to each other. The values of determination coefficient, $\mathrm{R}^{2}$, between $\triangle \mathrm{LA}$ and $\triangle \mathrm{MaxAasC}$ or $\triangle \mathrm{LogP}$ are equal to 0.39 and 0.24 , respectively. The correlation between last two descriptors is even lower $\left(R^{2}=0.10\right)$. Taking all these observations into account, it is rational to assume that for coformers screening the values of $\Delta \mathrm{LA} \geq 3.61$ seems to be a sufficiently accurate criterion for classification of dissolution rate enhancement of cocrystals formed with active pharmaceutical ingredients. It is worth mentioning, that the value of $\triangle \mathrm{LA}$ maximizing TP\% at $95 \%$ confidence corresponds also to the maximum of Matthews correlation coefficient distribution (Matthews, 1975). This index is a measure 
of correlation between the observed and predicted binary classifications and adopts values in the $<-1,+1>$ range. It is worth mentioning that $\mathrm{MCC}$ is a contingency matrix method of calculating the Pearson product-moment correlation coefficient and has essentially the same interpretation (Powers, 2011). Hence, it relies on ranking rather than mean values as in the case of ordinary correlation coefficient. The interpretation of MCC values is straightforward since +1 value represents a perfect match and -1 value denotes the total disagreement between prediction and observation. Finally, a zero denotes no better than random prediction. Hence, the maximization of MCC offering a quite useful criterion for quantification of theoretical approaches (Cysewski, 2016a) additionally confirms that the proposed method for threshold values is statistically meaningful. In the case analyzed here, the MCC reached a value of 0.54 suggesting a quite modest but acceptable performance of the statistical classification.

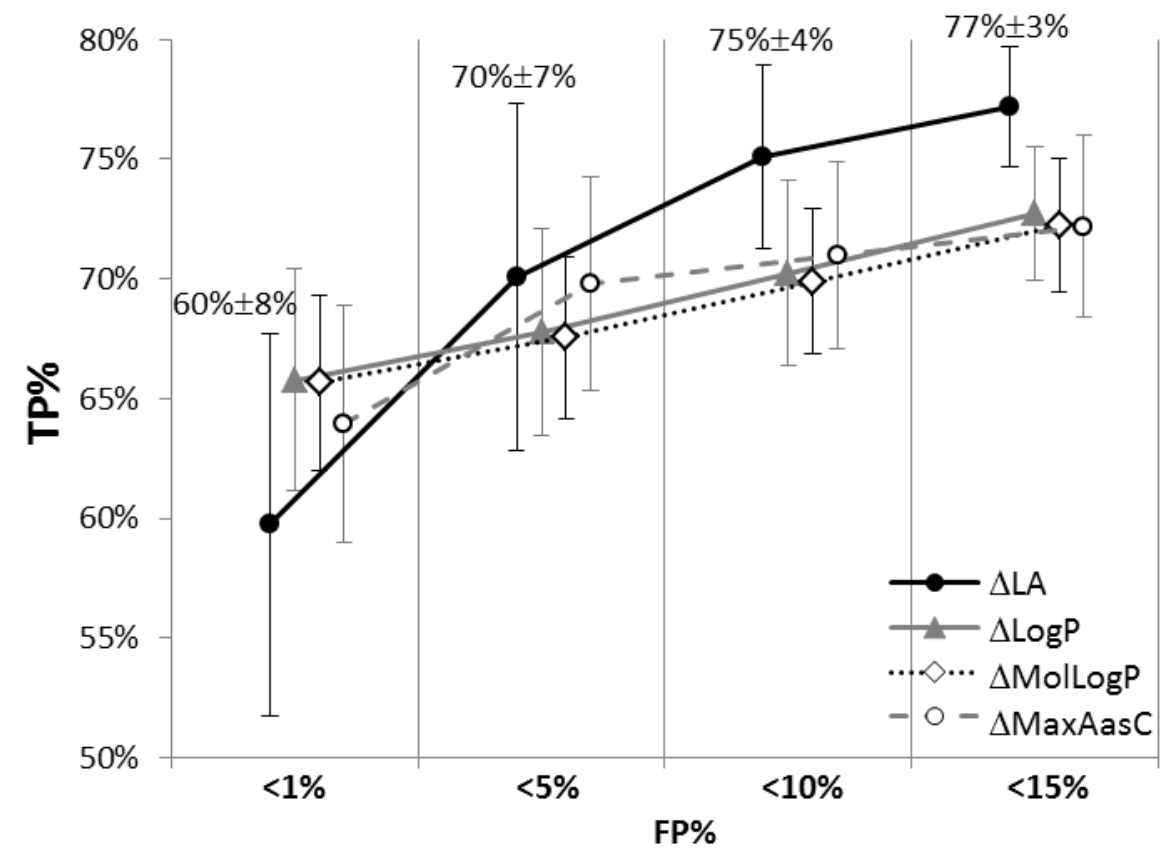

\begin{tabular}{lrrrr}
\hline & $\mathrm{FP} \%<1 \%$ & $\mathbf{F P} \%<5 \%$ & $\mathrm{FP} \%<10 \%$ & $\mathrm{FP} \%<15 \%$ \\
$\Delta \mathrm{LA}^{1}$ & $4.30 \pm 0.68$ & $3.61 \pm 0.24$ & $3.16 \pm 0.09$ & $2.84 \pm 0.06$ \\
$\Delta$ LogP $^{2}$ & $2.20 \pm 0.08$ & $2.10 \pm 0.07$ & $1.98 \pm 0.05$ & $1.85 \pm 0.04$ \\
$\Delta$ MolLogP $^{3}$ & $2.21 \pm 0.10$ & $2.11 \pm 0.10$ & $1.98 \pm 0.05$ & $1.86 \pm 0.05$ \\
$\Delta$ MaxAasC $^{1}$ & $0.60 \pm 0.60$ & $0.57 \pm 0.57$ & $0.53 \pm 0.53$ & $0.49 \pm 0.49$
\end{tabular}

Fig.1. Threshold values of selected molecular descriptors affecting distributions of false positive (FP\%) and true positive (TP\%) percentages. The relative values representing differences between molecular descriptors values characterizing drugs with respect of excipients were added below plots $\left({ }^{1} \mathrm{PaDEL},{ }^{2}\right.$ Chemopy, ${ }^{3}$ RDFKit). Error bars represent the standard deviation determined for 20 randomly selected subsets containing $50 \%$ of DSR dataset.

\subsection{Exemplary applications}

The above formulated criterions of coformers selection for increasing of cocrystals solubility rate do not include a very important question, whether the homogeneous bi-molecular complex is to be formed. It is well known that the outcome of solidification either as binary eutectics or cocrystal cannot be generally predicted from chemical formula (Cysewski, 2016a, 2016b). However, the probability of intermolecular complex formation in the solid state and quantification of the probability of cocrystal formation can be determined by computing the values of mixing enthalpy (Cysewski, 2016a). This indispensable additional criterion is a well-accepted measure of cocrystallization propensity. This kind of quantification of coformers affinity was successfully used for experimentally verified cocrystals screening (Cysewski, 2017, 2016a; Cysewski et al., 2016; Klamt, 2012, 2011; Klamt et al., 2002; Klamt and Schüürmann, 1993; Loschen and Klamt, 2015; Przybyłek et 
al., 2016b). In order to demonstrate the usefulness of the screening procedure proposed here, the search for DSR enhancers was extended over a quite comprehensive set of coformers defined in the methodology part. The potential pairs of drug and excipient were classified according to both high probability of cocrystal formation and a high chance for improvement of the dissolution rate by the following conjunction $\mathrm{H}_{\text {mix }}<-0.18$ and $\Delta \mathrm{LA}>3.61$. This region can be identified by right-bottom quadrant on figures presenting the distributions of relative values of lipoaffinity index as a function of mixing enthalpy.

\subsubsection{Prediction of DSR enhancement of Iloperidone}

lloperidone is an atypical antipsychotic for the treatment of schizophrenia symptoms. The improvement in cognition of schizophrenic patients is attributed to its activity as dopamine D2 and 5HT2A receptor antagonist. Although it is practically insoluble in water, the bioavailability of this medicament is as high as $96 \%$ due to good absorption from the GI tract. The maximal concentration is reached within 2-4 hours. This is achieved by tableting with very efficient dispersing agents. Alternatively, the increase of water solubility might be obtained via cocrystallization with an appropriate solubility enhancer. Indeed, such compounds as 3,5-dihydroxybenzoic acid, 3hydroxybenzoic acid or 2,3-dihydroxybenzoic acid were found (Zhang et al., 2013) to be well suited for this purpose. It is interesting to see if other compounds can also be used for improvement of dissolution rate of this drug. For this purpose the whole two-step screening procedure was applied and values of $\triangle L A$ and $H_{\text {mix }}$ were estimated for all pairs of potential cocrystals formed with solids belonging to EAFUS/GRAS list. As a result, the distributions of these chemometric measures were obtained and plotted in Fig.2. Inspection of these data leads to the conclusion that there is a broad range of compounds which might be considered as dissolution rate enhancers. Although many pairs comprising lloperidone fulfil the criterion of lower lipoaffinity compared to lloperidone, there are also numerous cases excluded due to low probability of cocrystallization. Thus, $\mathrm{H}_{\text {mix }}$ criterion is quite restrictive in the case of lloperidone pairs. There is a relatively low number of cases, which were additionally excluded due to too low values of $\Delta \mathrm{LA}$. In total, as many as 141 potential coformers might be advised for experimental screening as indicated in Fig. 2 by green circles located in the rightbottom quadrant. The three cocrystals studied experimentally are also found in the target window. Ten new cocrystals of the highest relative values of lipoaffinity index were enumerated in Fig.2. In this subset the first two compounds, Inositol and Sucralose, are rich in hydroxyl groups and the rest are carboxylic acids. The full list of dissolution rate enhancers of lloperidone identified by the applied screening procedure is provided in supporting materials (see Table S3). On this list one can find not only other carboxylic acids but also some amines, heterocyclic compounds and other polar compounds.

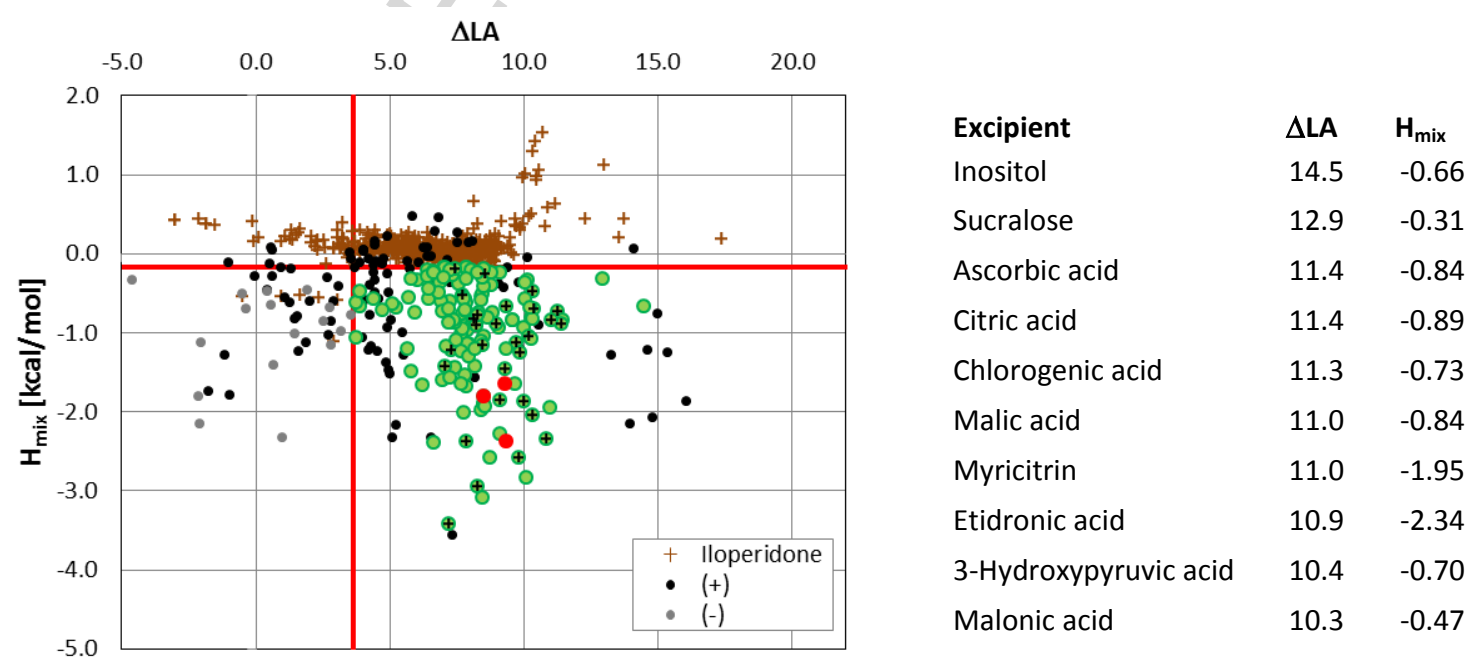

Fig.2. The distributions of relative values of lipoaffinity index $(\Delta \mathrm{LA})$ as a function of mixing enthalpy $\left(\mathrm{H}_{\text {mix }}\right)$ characterizing pairs formed by lloperidone and all solid coformers found on EAFUS/GRAS list. Potential cocrystals with enhanced dissolution rate are represented by green circles. Experimentally 
confirmed positive examples are denoted by red circles. Black plus signs denote cases with high probability of salt formation ( $\Delta \mathrm{pKa}>2.7)$.

\subsubsection{Prediction of DSR enhancement of Ritonavir}

Second example documents the results of classification of potential cocrystals of Ritonavir. This antiretroviral drug, sold under the trade name Norvir, is used to treat HIV/AIDS and takes active part in combination treatment known as highly active antiretroviral therapy (HAART). Ritonavir is a protease inhibitor with activity against Human Immunodeficiency Virus Type 1 (HIV-1). It can be administered either in the form of capsules or tablets but the latter are preferred from the bioavailability point of view. It is classified as practically non-soluble in water what might justify the cocrystals screening for solubility enhancement. Interestingly, many potential binary solids are worth studying experimentally as it was documented in Fig.3. There are as many as 302 coformers resulting from the performed screening procedure. The top ten cases are enumerated in Fig.3., while the rest are collected in supporting materials (see Table S4). Also in the case of Ritonavir, all three experimentally studied systems are found in the target quadrant in Fig.3.

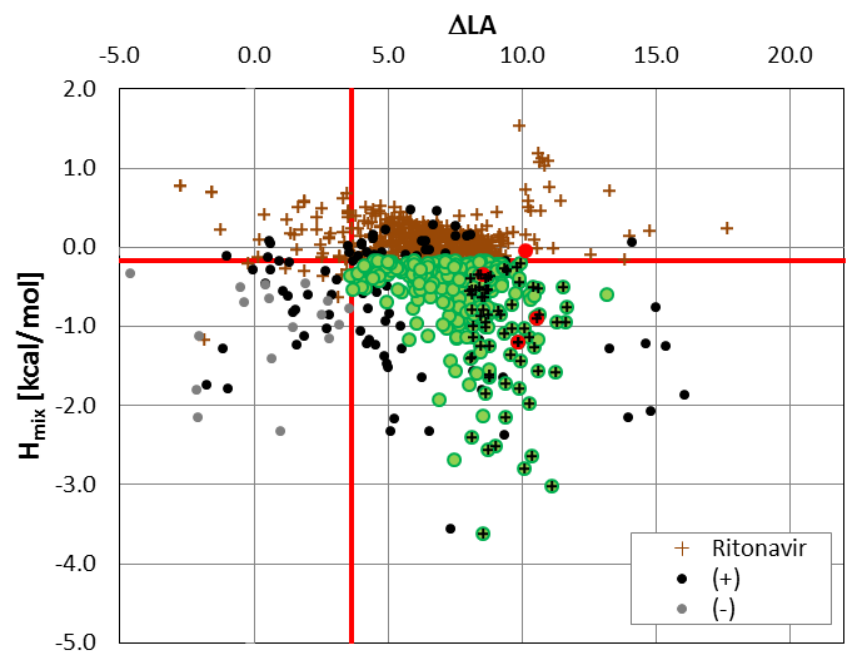

$\begin{array}{lcc}\text { Excipient } & \Delta \mathrm{LA} & \mathbf{H}_{\text {mix }} \\ \text { Sucralose } & 13.2 & -0.6 \\ \text { Ascorbic acid } & 11.7 & -0.8 \\ \text { Citric acid } & 11.7 & -0.9 \\ \text { Chlorogenic acid } & 11.5 & -0.5 \\ \text { Malic acid } & 11.3 & -0.9 \\ \text { Myricitrin } & 11.3 & -1.6 \\ \text { Etidronic acid } & 11.1 & -3.0 \\ \text { 4-Hydroxyphenylpyruvic acid } & 10.6 & -0.9 \\ \text { Malonic acid } & 10.6 & -0.5 \\ \text { Sulfamic acid } & 10.6 & -1.6\end{array}$

Fig.3. The distributions of relative values of lipoaffinity index $(\Delta L A)$ as a function of mixing enthalpy $\left(\mathrm{H}_{\text {mix }}\right)$ characterizing pairs formed by Ritonavir and all solid coformers found on EAFUS/GRAS list. Potential cocrystals with enhanced dissolution rate are represented by green circles. Experimentally confirmed positive examples are denoted by red circles. Black plus signs denote cases with high probability of salt formation ( $\Delta \mathrm{pKa}>2.7)$.

\subsubsection{Prediction of DSR enhancement of Carbamazepine}

The third drug was selected for documenting some problematic cases. Carbamazepine sold under a variety of tradenames is a drug primarily used in the treatment of neuropathic pain and epilepsy. Its anticonvulsant activity is granted from structural similarities to tricyclic antidepressants and the capability to inhibit sustained repetitive firing by blocking use-dependent sodium channels. The synaptic transmission blockage in the trigeminal nucleus and seizure control is attributed to pain relief and reduction of post-tetanic potentiation of synaptic transmission in the spinal cord. Carbamazepine also possesses many other therapeutic effects including anticholinergic, central antidiuretic, antiarrhythmic, muscle relaxant, antidepressant, sedative, and neuromuscular-blocking properties. Carbamazepine is sparsely soluble in water $(17.7 \mathrm{mg} / \mathrm{L}$, https://www.drugbank.ca/) and in clinical studies both suspensions and conventional tablets are used with varying bioavailability, both in the terms of time to peak concentration and percentage of absorption. It seems then to be interesting to find excipients affecting the dissolution rate of Carbamazepine. In Fig.4 there are presented the results of applied screening procedure. What is directly visible in the case of this drug, not all of experimentally studied systems were found within the target predictive region. This is the cost of binary classification, which excluded almost one fifth of systems despite the fact that they belong to true positive cases. This misfortunate situation is somewhat compensated with a relatively high number of other potential DSR enhancers. Indeed, as many as 114 cases were identified as 
potential coformers interesting from the perspective of dissolution rate improvement as enumerated in Table S5. The best ten were collected in Fig.4. Although they all show quite modest affinities toward Carbamazepne, what is indicated by relatively high $\mathrm{H}_{\text {mix }}$ values, they are still found within the target quadrant. It is worth noting that the majority of selected dissolution rate enhancers are aliphatic and aromatic acidic compounds including phenolic acids, aliphatic dicarboxylic and hydroxycarboxylic acids. Apart from dissolution rate, these promising classes of coformers have been extensively studied in the context of improving carbamazepine solubility (Childs et al., 2008; Good and Rodríguez-Hornedo, 2009; Shayanfar et al., 2013; Ullah et al., 2016). Unfortunately only very few reports on the bioavailability of carbamazepine cocrystals can be found in the literature (Hickey et al., 2007; Ullah et al., 2016).

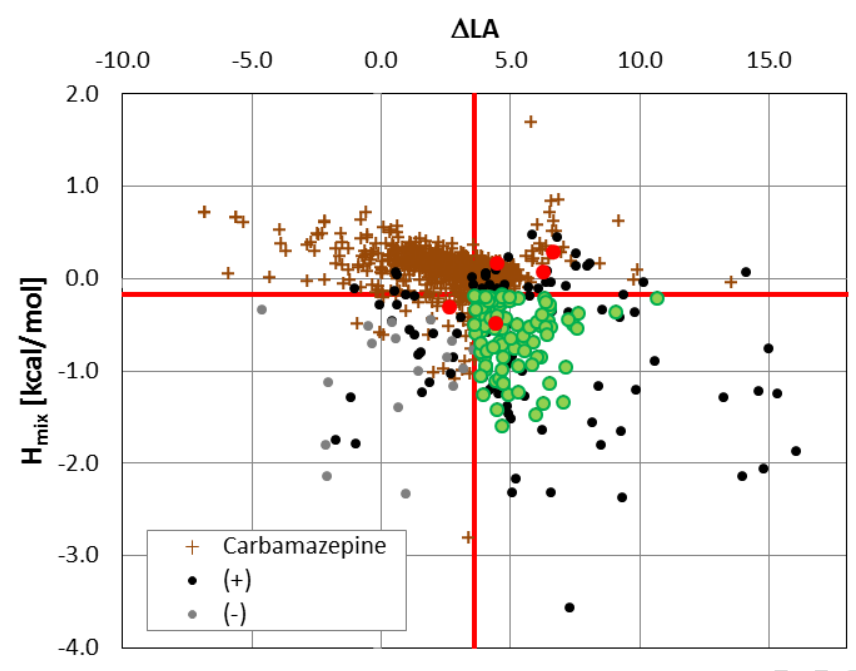

Excipient
Inositol
Sucralose
Ascorbic acid
Citric acid
Chlorogenic acid
Malic acid
Myricitrin
Etidronic acid
4-Hydroxyphenylpyruvic acid
Malonic acid

$\begin{array}{rr}\Delta \mathrm{LA} & \mathrm{H}_{\text {mix }} \\ 10.7 & -0.2 \\ 9.1 & -0.3 \\ 7.6 & -0.3 \\ 7.6 & -0.5 \\ 7.4 & -0.5 \\ 7.2 & -0.4 \\ 7.2 & -0.9 \\ 7.0 & -1.3 \\ 6.6 & -0.5 \\ 6.5 & -0.3\end{array}$

Fig.4. The distributions of relative values of lipoaffinity index $(\Delta \mathrm{LA})$ as a function of mixing enthalpy $\left(\mathrm{H}_{\text {mix }}\right)$ characterizing pairs formed by Carbamazepine and all solid coformers found on EAFUS/GRAS list. Potential cocrystals with enhanced dissolution rate are represented by green circles. Experimentally confirmed positive examples are denoted by red circles.

\subsubsection{Prediction of DSR enhancement of Ethenzamide}

For the above presented examples of cocrystals the application of screening procedure identified many candidates for dissolution rate enhancers. However, it is worth mentioning that not all drugs are so prone to cocrystallization with dissolution rate improvement. Ethenzamide seems to be such a case. This popular analgesic and antipyretic agent is a non-prescription drug belonging to non-steroidal anti-inflammatory agents with medicinal uses similar to those of aspirin. It is typically administered in combination with other components as Acetaminophen, Aspirin or Caffeine in the over-the-counter pain remedies. For this last example analyzed here only few new cocrystals of improved DSR can be suggested. Fortunately, all six experimentally studied cases were also positively identified by the applied procedure, but the list of new coformers is not very long. This indicates that it will be probably quite difficult to find effective enhancers of dissolution rate of Enthenzamide via cocrystallization. Apart from ten coformers listed in Fig. 5 there were found only thirteen additional ones, collected in supporting materials (see Table S6). 


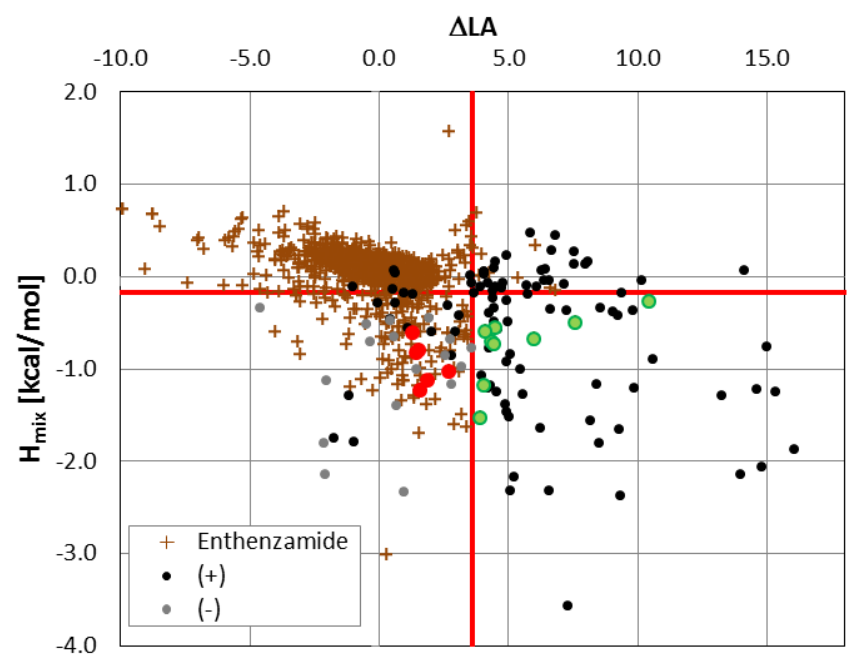

$\begin{array}{lrc}\text { Excipient } & \Delta \text { LA } & \mathbf{H}_{\text {mix }} \\ \text { Sucrose } & 10.4 & -0.3 \\ \text { Inositol } & 7.6 & -0.5 \\ \text { Ascorbic acid } & 4.5 & -0.6 \\ \text { Citric acid } & 4.5 & -0.7 \\ \text { Chlorogenic acid } & 4.3 & -0.7 \\ \text { Malic acid } & 4.1 & -0.6 \\ \text { Myricitrin } & 4.1 & -1.2 \\ \text { Etidronic acid } & 3.9 & -1.5 \\ \text { Hydroxypyruvic acid } & 3.4 & -0.7 \\ \text { Malonic acid } & 3.4 & -0.4 \\ \text { Sulfamic acid } & 3.4 & -1.6\end{array}$

Fig.5. The distributions of relative values of lipoaffinity index $(\Delta \mathrm{LA})$ as a function of mixing enthalpy $\left(H_{\text {mix }}\right)$ characterizing pairs formed by enthenzamide and all considered coformers. Potential cocrystals with enhanced dissolution rate are represented by green circles. Experimentally confirmed positive examples are denoted by red circles.

\section{Conclusions}

Recently there has been a growing interest in in-silico pharmaceutical excipients screening methods including bioavailability and solubility improvement agents such as soluble polymers, surfactants and nutraceutical cocrystals formers (Bergström et al., 2016; Christensen et al., 2017; Cysewski, 2017; Przybyłek et al., 2017). The major advantage of efficient theoretical approaches, important from the economic viewpoint, is reducing the time and reagents costs. The large number of experimental data available in the literature gives the opportunity to build models for predicting many pharmaceutically relevant features. However, the main problem with solubility and dissolution rate modeling are non-homogeneous experimental data sets. However, for the screening purposes, qualitative physicochemical properties classification methods can be very useful for providing an initial overview of the excipients applicability. The search for enhancers of drugs dissolutions rate is dictated by the importance of drugs bioavailability control. Although there are many ways of water dissolution improvement, the cocrystallization with appropriate excipient is one of the most common approaches. This paper documented a new way of classification of potential cocrystal formers into four classes depending on the values of mixing enthalpy and relative value of lipoaffinity index (expressed as the difference between descriptor calculated for API and excipient). The whole procedure relied on the training set comprising positive and negative cases of cocrystals found in the literature. The formers included 102 drug-excipient pairs for which experimentally proven increase of dissolution rate was observed with respect of pure drug. The latter set comprised 17 cocrystals for which such effect was not observed. Despite the fact that the only available data were of qualitative character, the performed binary classification statistical analysis allowed to formulate quantitative criterions. Among considered 3679 molecular descriptors the relative value of lipoaffinity index has been found as the most appropriate measure suited for discrimination of positive and negative cases. Assuming $5 \%$ precision the applied classification criterion led to inclusion of $70 \%$ positive cases in the final prediction. Since lipoaffinity index is a molecular descriptor computed using 2D information about a chemical structure, its estimation is straightforward and computationally inexpensive. The inclusion of additional criterion characterizing the cocrystallization probability completed the requirements for an effective and reliable theoretical screening procedure. The practical applications require only the computation of the relative value of lipoaffinity index of excipient with respect of considered drug and additionally their mutual affinity expressed in terms of $\mathrm{H}_{\text {mix }}$ values. Hence, the conjunction criterion can be formulated as follows:

$$
\left\{\begin{array}{c}
\Delta \mathrm{LA}>3.61 \\
\mathrm{H}_{\text {mix }}<-0.18
\end{array}\right.
$$


From the graphical point of view this corresponds to the right-bottom quadrant of $\Delta L A$ distributions plotted against $\mathrm{H}_{\text {mix }}$ values. Hence, the practice of theoretical screening is very straightforward, provided that the collections of these two molecular descriptors are available. The values of $\triangle \mathrm{LA}$ can be computed virtually for any compound using freely available software (Yap, 2011). The computation of $\mathrm{H}_{\text {mix }}$ values requires a commercial program, what is also not a restrictive requirement since it is considered as a standard of first principle thermodynamics computations (Klamt, 2012, 2011; Klamt et al., 2002; Klamt and Schüürmann, 1993).

What is worth mentioning, the sets of promising coformers can be identified for many drugs as detailed in provided supplementary materials. These lists offer experimentalist the first choice selection of compounds for screening of dissolution rate improvements and will be used also in our laboratory for future projects. Since the applied statistical procedure was formulated using $5 \%$ precision, it is also expected that the same accuracy is associated with provided sets of potential coformers. It is also important to notice that almost one third (30\%) of actual true positive cases are excluded from the analysis due to the limited nature of discriminating power of lipoaffinity index itself. However, this molecular descriptor was found to be the best among many other indices. From the practical point of view finding all of DSR enhancers is not really necessary since any success in finding of at least some is sufficient for new forms of drugs developments. It should be however noted that there are not many negative examples available in the literature and therefore further studies should be carried out to find more precise cocrystal dissolution rate improvement criterions.

\section{Acknowledgements}

Technical assistance of Anna Cieślińska (MD) and Tomasz Miernik (MD) during computations and preparation of the manuscript is appreciated.

\section{References}

Aitipamula, S., Wong, A.B.H., Chow, P.S., Tan, R.B.H., 2012. Pharmaceutical cocrystals of ethenzamide: structural, solubility and dissolution studies. CrystEngComm 14, 8515-8524. doi:10.1039/c2ce26325d

Amodwala, S., Kumar, P., Thakkar, H.P., 2017. Statistically optimized fast dissolving microneedle transdermal patch of meloxicam: A patient friendly approach to manage arthritis. Eur. J. Pharm. Sci. 104, 114-123. doi:10.1016/j.ejps.2017.04.001

Apshingekar, P.P., Aher, S., Kelly, A.L., Brown, E.C., Paradkar, A., 2017. Synthesis of caffeine/maleic acid co-crystal by ultrasound-assisted slurry co-crystallization. J. Pharm. Sci. 106, 66-70. doi:10.1016/j.xphs.2016.09.009

Arafa, M.F., El-Gizawy, S.A., Osman, M.A., El Maghraby, G.M., 2016. Xylitol as a potential co-crystal co-former for enhancing dissolution rate of felodipine: preparation and evaluation of sublingual tablets. Pharm. Dev. Technol. 1-45. doi:10.1080/10837450.2016.1242625

Bag, P.P., Patni, M., Malla Reddy, C., 2011. A kinetically controlled crystallization process for identifying new co-crystal forms: fast evaporation of solvent from solutions to dryness. CrystEngComm 13, 5650-5652. doi:10.1039/c1ce05778b

Bag, P.P., Reddy, C.M., 2012. Screening and selective preparation of polymorphs by fast evaporation method: A case study of aspirin, anthranilic acid, and niflumic acid. Cryst. Growth Des. 12, 2740-2743. doi:10.1021/cg300404r

Bak, A., Gore, A., Yanez, E., Stanton, M., Tufekcic, S., Syed, R., Akrami, A., Rose, M., Surapaneni, S., Bostick, T., King, A., Neervannan, S., Ostovic, D., Koparkar, A., 2008. The co-crystal approach to improve the exposure of a water-insoluble compound: AMC 517 sorbic acid co-crystal characterization and pharmacokinetics. J. Pharm. Sci. 97, 3942-3956. doi:10.1002/jps.21280

Bergström, C.A.S., Charman, W.N., Porter, C.J.H., 2016. Computational prediction of formulation strategies for beyond-rule-of-5 compounds. Adv. Drug Deliv. Rev. 101, 6-21. doi:10.1016/j.addr.2016.02.005

Bethune, S.J., Schultheiss, N., Henck, J.O., 2011. Improving the poor aqueous solubility of nutraceutical compound pterostilbene through cocrystal formation. Cryst. Growth Des. 11, 2817-2823. doi:10.1021/cg1016092 
Brough, C., Miller, D.A., Keen, J.M., Kucera, S.A., Lubda, D., Williams, R.O., 2015. Use of polyvinyl alcohol as a solubility-enhancing polymer for poorly water soluble drug delivery (Part 1). AAPS PharmSciTech 17, 180-190. doi:10.1208/s12249-015-0458-y

Brown, R., 2012. Investigating pharmaceutical co-crystals as a means to improve the solubility of a drug. University of Kansas.

Cao, D., Xu, Q., Hu, Q., Liang, Y., 2013. ChemoPy: freely available python package for computational biology and chemoinformatics. Bioinformatics 29. doi:10.1093/bioinformatics/btt105

Chadha, R., Bhandari, S., Haneef, J., Khullar, S., Mandal, S., Pidocck, E., Monge, L.R., Taylor, T., Streek, J. Van de, Wood, P.A., 2014. Cocrystals of telmisartan: characterization, structure elucidation, in vivo and toxicity studies. CrystEngComm 16, 8375. doi:10.1039/C4CE00797B

Chadha, R., Saini, A., Arora, P., Chanda, S., Jain, D.V.S., 2012. Cocrystals of efavirenz with selected conformers: Preparation and characterization. Int. J. Pharm. Pharm. Sci. 4, 244-250.

Chen, Y., Li, L., Yao, J., Ma, Y.Y., Chen, J.M., Lu, T.B., 2016. Improving the solubility and bioavailability of apixaban via apixaban-oxalic acid cocrystal. Cryst. Growth Des. 16, 2923-2930. doi:10.1021/acs.cgd.6b00266

Cheney, M.L., Weyna, D.R., Shan, N., Hanna, M., Wojtas, L., Zaworotko, M.J., 2011. Coformer selection in pharmaceutical cocrystal development: a case study of a meloxicam aspirin cocrystal that exhibits enhanced solubility and pharmacokinetics. J. Pharm. Sci. 100, 2172-2181. doi:10.1002/jps.22434

Cherukuvada, S., Babu, N.J., Nangia, A., 2011. Nitrofurantoin-p-aminobenzoic acid cocrystal: Hydration stability and dissolution rate studies. J. Pharm. Sci. 100, 3233-3244. doi:10.1002/jps.22546

Childs, S.L., 2009. Metronidazole cocrystals and imipramine cocrystals U.S. Patent 20090258859 A1.

Childs, S.L., Kandi, P., Lingireddy, S.R., 2013. Formulation of a danazol cocrystal with controlled supersaturation plays an essential role in improving bioavailability. Mol. Pharm. 10, 3112-3127. doi:10.1021/mp400176y

Childs, S.L., Rodríguez-Hornedo, N., Reddy, L.S., Jayasankar, A., Maheshwari, C., McCausland, L., Shipplett, R., Stahly, B.C., 2008. Screening strategies based on solubility and solution composition generate pharmaceutically acceptable cocrystals of carbamazepine. CrystEngComm. doi:10.1039/b715396a

Choi, J.-S., Park, J.-S., 2017. Design of PVP/VA S-630 based tadalafil solid dispersion to enhance the dissolution rate. Eur. J. Pharm. Sci. 97, 269-276. doi:10.1016/j.ejps.2016.11.030

Christensen, J.R., Meng-Lund, H., Grohganz, H., Poso, A., Laitinen, T., Korhonen, O., Jørgensen, L., Pajander, J., 2017. Surface area, volume and shape descriptors as a novel tool for polymer lead design and discovery. Eur. J. Pharm. Sci. 102, 188-195. doi:10.1016/j.ejps.2017.03.013

Chun, N.H., Lee, M.J., Song, G.H., Chang, K.Y., Kim, C.S., Choi, G.J., 2014. Combined anti-solvent and cooling method of manufacturing indomethacin-saccharin (IMC-SAC) co-crystal powders. J. Cryst. Growth 408, 112-118. doi:10.1016/j.jcrysgro.2014.07.057

COSMOlogic GmbH \& Co. KG, 2016. COSMOthermX Version C3.0.1601.

Cysewski, P., 2017. In silico screening of dicarboxylic acids for cocrystallization with phenylpiperazine derivatives based on both cocrystallization propensity and solubility advantage. J. Mol. Model. 23, 136. doi:10.1007/s00894-017-3287-y

Cysewski, P., 2016a. Efficacy of bi-component cocrystals and simple binary eutectics screening using heat of mixing estimated under super cooled conditions. J. Mol. Graph. Model. 68, 23-28. doi:10.1016/j.jmgm.2016.06.003

Cysewski, P., 2016b. Heat of formation distributions of components involved in bi-component cocrystals and simple binary eutectic mixtures. New J. Chem. 40, 187-194. doi:10.1039/C5NJ02013A

Cysewski, P., Przybyłek, M., Ziółkowska, D., Mroczyńska, K., 2016. Exploring the cocrystallization potential of urea and benzamide. J. Mol. Model. 22, 103. doi:10.1007/s00894-016-2964-6

Danjo, K., Nataka, T. \& Otsuka, A., 1997. Preparation and dissolution behavior of ethenzamide solid dispersion using various sugars as dispersion carriers. Chem. Pharm. Bull. 45, 1840-1844. doi:10.1248/cpb.45.1840 
Dizaj, S.M., Vazifehasl, Z., Salatin, S., Adibkia, K., Javadzadeh, Y., 2015. Nanosizing of drugs: Effect on dissolution rate. Res. Pharm. Sci. 10, 95-108.

Dong, J., Cao, D.-S., Miao, H.-Y., Liu, S., Deng, B.-C., Yun, Y.-H., Wang, N.-N., Lu, A.-P., Zeng, W.-B., Chen, A.F., 2015. ChemDes: an integrated web-based platform for molecular descriptor and fingerprint computation. J. Cheminform. 7, 60. doi:10.1186/s13321-015-0109-z

Dua, K., Pabreja, K., Ramana, M. V, Lather, V., 2011. Dissolution behavior of $\beta$-cyclodextrin molecular inclusion complexes of aceclofenac. J. Pharm. Bioallied Sci. 3, 417-25. doi:10.4103/09757406.84457

FDA, 2017. USA Food and Drug Administration [WWW Document]. URL https://www.fda.gov/default.htm

Foglio Bonda, A., Rinaldi, M., Segale, L., Palugan, L., Cerea, M., Vecchio, C., Pattarino, F., 2016. Nanonized itraconazole powders for extemporary oral suspensions: Role of formulation components studied by a mixture design. Eur. J. Pharm. Sci. 83, 175-183. doi:10.1016/j.ejps.2015.12.030

Gadade, D.D., Pekamwar, S.S., Lahoti, S.R., Patni, S.D., Sarode, M.C., 2017. Cocrystallization of etodolac: prediction of cocrystallization, synthesis, solid state characterization and in vitro drug release. Marmara Pharm. J. 21. doi:10.12991/MPJ.10921

Gao, Y., Zu, H., Zhang, J., 2011. Enhanced dissolution and stability of adefovir dipivoxil by cocrystal formation. J. Pharm. Pharmacol. 63, 483-490. doi:10.1111/j.2042-7158.2010.01246.x

Ghanbarzadeh, S., Khalili, A., Jouyban, A., Emami, S., Javadzadeh, Y., Solhi, M., Hamishehkar, H., 2016. Dramatic improvement in dissolution rate of albendazole by a simple, one-step, industrially scalable technique. Res. Pharm. Sci. 11, 435-444. doi:10.4103/1735-5362.194868

Good, D.J., Rodríguez-Hornedo, N., 2009. Solubility Advantage of Pharmaceutical Cocrystals. Cryst. Growth Des. 9, 2252-2264. doi:10.1021/cg801039j

Goud, N.R., Khan, R.A., Nangia, A., 2014. Modulating the solubility of sulfacetamide by means of cocrystals. CrystEngComm 16, 5859-5869. doi:10.1039/c4ce00103f

Gramatica, P., Corradi, M., Consonni, V., 2000. Modelling and prediction of soil sorption coefficients of non-ionic organic pesticides by molecular descriptors. Chemosphere 41, 763-777. doi:10.1016/S0045-6535(99)00463-4

Grossjohann, C., Eccles, K.S., Maguire, A.R., Lawrence, S.E., Tajber, L., Corrigan, O.I., Healy, A.M., 2012. Characterisation, solubility and intrinsic dissolution behaviour of benzamide: dibenzyl sulfoxide cocrystal. Int. J. Pharm. 422, 24-32. doi:10.1016/j.ijpharm.2011.10.016

Guha, R., Dexheimer, T.S., Kestranek, A.N., Jadhav, A., Chervenak, A.M., Ford, M.G., Simeonov, A., Roth, G.P., Thomas, C.J., 2011. Exploratory analysis of kinetic solubility measurements of a small molecule library. Bioorg. Med. Chem. 19, 4127-34. doi:10.1016/j.bmc.2011.05.005

Gujar, P.P., Kokil, A.A., Karekar, P.S., Gurav, Y.A., Yadav, A. V, 2013. Improvement in physicochemical properties of nevirapine. Int. J. Pharm. Technol. IJPT 4, 4831-4842.

Haeria, A.N.N., Isriany, I., 2015. Characterization and dissolution test of aspirin-nicotinamide cocrystal. Int. J. Pharm Tech Res. 8, 166-170.

Hall, L.H., Kier, L.B., 1995. Electrotopological State Indices for Atom Types: A Novel Combination of Electronic, Topological, and Valence State Information. J. Chem. Inf. Model. 35, 1039-1045. doi:10.1021/ci00028a014

Hasa, D., Schneider Rauber, G., Voinovich, D., Jones, W., 2015. Cocrystal Formation through Mechanochemistry: from Neat and Liquid-Assisted Grinding to Polymer-Assisted Grinding. Angew. Chemie Int. Ed. 54, 7371-7375. doi:10.1002/anie.201501638

Hickey, M.B., Peterson, M.L., Scoppettuolo, L.A., Morrisette, S.L., Vetter, A., Guzmán, H., Remenar, J.F., Zhang, Z., Tawa, M.D., Haley, S., Zaworotko, M.J., Almarsson, Ö., 2007. Performance comparison of a co-crystal of carbamazepine with marketed product. Eur. J. Pharm. Biopharm. 67, 112-119. doi:10.1016/j.ejpb.2006.12.016

Hiendrawan, S., Veriansyah, B., Widjojokusumo, E., Soewandhi, S.N., Wikarsa, S., Tjandrawinata, R.R., 2016. Simultaneous cocrystallization and micronization of paracetamol-dipicolinic acid cocrystal by supercritical antisolvent (SAS). Int. J. Pharm. Pharm. Sci. 8, 89-98.

Hoffman, M., Lindeman, J.A., 2012. Co-crystals : Commercial Opportunities and Patent 
Considerations, in: Wouters, J., Quéré, L. (Eds.), Pharmaceutical Salts and Co-Crystals, RSC Drug Discovery. Royal Society of Chemistry, Cambridge, pp. 318-329. doi:10.1039/978184973350200318

Huang, Y., Zhang, B., Gao, Y., Zhang, J., Shi, L., 2014. Baicalein-nicotinamide cocrystal with enhanced solubility, dissolution, and oral bioavailability. J. Pharm. Sci. 103, 2330-2337. doi:10.1002/jps.24048

Ibrahim, M.M., EL-Nabarawi, M., El-Setouhy, D.A., Fadlalla, M.A., 2010. Polymeric surfactant based etodolac chewable tablets: formulation and in vivo evaluation. AAPS PharmSciTech 11, 17301737. doi:10.1208/s12249-010-9548-z

Ige, P.P., Agrawal, K., Patil, U., 2015. Enhanced in vitro dissolution of Iloperidone using Caesalpinia Pulcherrima mucoadhesive microspheres. Beni-Suef Univ. J. Basic Appl. Sci. 4, 26-32. doi:10.1016/j.bjbas.2015.02.004

Imchalee, R., Charoenchaitrakool, M., 2015. Gas anti-solvent processing of a new sulfamethoxazole-I-malic acid cocrystal. J. Ind. Eng. Chem. 25, 12-15. doi:10.1016/j.jiec.2014.11.009

Info, A., 2013. ENHANCEMENT OF SOLUBILITY AND DISSOLUTION RATE OF TELMISARTAN BY. Int. J. Pharm. Pharm. Sci. 3, 423-426.

Jain, T., Sheokand, S., Modi, S.R., Ugale, B., Yadav, R.N., Kumar, N., Nagaraja, C.M., Bansal, A.K., 2017. Effect of differential surface anisotropy on performance of two plate shaped crystals of aspirin form I. Eur. J. Pharm. Sci. 99, 318-327. doi:10.1016/j.ejps.2016.12.034

Jitkar, S., Thipparaboina, R., Chavan, R.B., Shastri, N.R., 2016. Spherical agglomeration of platy crystals: curious case of etodolac. Cryst. Growth Des. 16, 4034-4042. doi:10.1021/acs.cgd.6b00563

Jung, M.S., Kim, J.S., Kim, M.S., Alhalaweh, A., Cho, W., Hwang, S.J., Velaga, S.P., 2010. Bioavailability of indomethacin-saccharin cocrystals. J. Pharm. Pharmacol. 62, 1560-1568. doi:10.1111/j.20427158.2010.01189.x

Jung, S., Choi, I., Kim, I., 2015. Liquid-assisted grinding to prepare a cocrystal of adefovir dipivoxil thermodynamically less stable than its neat phase. Crystals 5, 583-591. doi:10.3390/cryst5040583

Kalepu, S., Nekkanti, V., 2015. Insoluble drug delivery strategies: review of recent advances and business prospects. Acta Pharm. Sin. B 5, 442-453. doi:10.1016/j.apsb.2015.07.003

Karki, S., Friščić, T., Jones, W., Motherwell, W.D.S., 2007. Screening for pharmaceutical cocrystal hydrates via neat and liquid-assisted grinding. Mol. Pharm. 4, 347-354. doi:10.1021/mp0700054

Keraliya, R.A., Soni, T.G., Thakkar, V.T., Gandhi, T.R., 2010. Effect of solvent on crystal habit and dissolution behavior of tolbutamide by initial solvent screening. Dissolution Technol. 17, 16-21. doi:10.14227/DT170110P16

Khadka, P., Ro, J., Kim, H., Kim, I., Kim, J.T., Kim, H., Cho, J.M., Yun, G., Lee, J., 2014. Pharmaceutical particle technologies: An approach to improve drug solubility, dissolution and bioavailability. Asian J. Pharm. Sci. 9, 304-316. doi:10.1016/j.ajps.2014.05.005

Khor, E.S., Wong, N.K., Soewandhi, S.N., 2016. Comparison study of therapeutic properties of proteins and secondary metabolites from Carica papaya, International Journal of Pharmacy and Pharmaceutical Sciences. Innovare Academics Sciences Pvt. Ltd.

Klamt, A., 2012. Solvent-screening and co-crystal screening for drug development with COSMO-RS. J. Cheminform. doi:10.1186/1758-2946-4-S1-014

Klamt, A., 2011. The COSMO and COSMO-RS solvation models. Wiley Interdiscip. Rev. Comput. Mol. Sci. 1, 699-709. doi:10.1002/wcms.56

Klamt, A., 1995. Conductor-like Screening Model for Real Solvents: A New Approach to the Quantitative Calculation of Solvation Phenomena. J. Phys. Chem. 99, 2224-2235. doi:10.1021/j100007a062

Klamt, A., Eckert, F., Hornig, M., Beck, M.E., Bürger, T., 2002. Prediction of aqueous solubility of drugs and pesticides with COSMO-RS. J. Comput. Chem. 23, 275-81. doi:10.1002/jcc.1168

Klamt, A., Schüürmann, G., 1993. COSMO: a new approach to dielectric screening in solvents with 
explicit expressions for the screening energy and its gradient. J. Chem. Soc. Perkin Trans. 2799. doi:10.1039/p29930000799

Kojima, T., Tsutsumi, S., Yamamoto, K., Ikeda, Y., Moriwaki, T., 2010. High-throughput cocrystal slurry screening by use of in situ Raman microscopy and multi-well plate. Int. J. Pharm. 399, 52-59. doi:10.1016/j.ijpharm.2010.07.055

Kojo, Y., Matsunaga, S., Suzuki, H., Sato, H., Seto, Y., Onoue, S., 2017. Improved oral absorption profile of itraconazole in hypochlorhydria by self-micellizing solid dispersion approach. Eur. J. Pharm. Sci. 97, 55-61. doi:10.1016/j.ejps.2016.10.032

Kumar, S.., 2014. Polymorphism and solubility of selected active pharmaceutical ingredients (Thesis). University of Hyderabad.

Lahamage, S.R., Darekar, A.B., Zalte, A.G., Saudagar, R.B., 2016. Co-crystal approach for improving poorly soluble drug agomelatine by using acid coformer for tablets. Hum. Journals Res. Artic. August 7, 19-34.

Lee, M.-J., Wang, I.-C., Kim, M.-J., Kim, P., Song, K.-H., Chun, N.-H., Park, H.-G., Choi, G.J., 2015. Controlling the polymorphism of carbamazepine-saccharin cocrystals formed during antisolvent cocrystallization using kinetic parameters. Korean J. Chem. Eng. 32, 1910-1917. doi:10.1007/s11814-014-0384-9

Li, S., Yu, T., Tian, Y., McCoy, C.P., Jones, D.S., Andrews, G.P., 2016. Mechanochemical synthesis of pharmaceutical cocrystal suspensions via hot melt extrusion: Feasibility studies and physicochemical characterization. Mol. Pharm. 13, 3054-3068. doi:10.1021/acs.molpharmaceut.6b00134

Liu, R., So, S.S., Sun, H., 2001. Development of quantitative structure-property relationship models for early ADME evaluation in drug discovery. 1. Aqueous solubility. J. Chem. Inf. Comput. Sci. 41, 1633-1639.

Liu, R., Sun, H., So, S., 2001. Development of Quantitative Structure - Property Relationship Models for Early ADME Evaluation in Drug Discovery . 2. Blood-Brain Barrier Penetration. J. Chem. Inf. Comput. Sci. 41, 1623-1632. doi:10.1021/ci010290i

Loschen, C., Klamt, A., 2015. Solubility prediction, solvate and cocrystal screening as tools for rational crystal engineering. J. Pharm. Pharmacol. 67, 803-11. doi:10.1111/jphp.12376

Lu, Y., Kim, S., Park, K., 2011. In vitro-in vivo correlation: perspectives on model development. Int. J. Pharm. 418, 142-8. doi:10.1016/j.ijpharm.2011.01.010

M Badr-Eldin, S., A Ahmed, T., R Ismail, H., 2013. Aripiprazole-cyclodextrin binary systems for dissolution enhancement: effect of preparation technique, cyclodextrin type and molar ratio. Iran. J. Basic Med. Sci. 16, 1223-31.

Maggi, L., Bruni, G., Maietta, M., Canobbio, A., Cardini, A., Conte, U., 2013. II. Technological approaches to improve the dissolution behavior of nateglinide, a lipophilic insoluble drug: Comilling. Int. J. Pharm. 454, 568-572. doi:10.1016/j.ijpharm.2013.06.085

Maghsoodi, M., 2015. Role of solvents in improvement of dissolution rate of drugs: crystal habit and crystal agglomeration. Adv. Pharm. Bull. 5, 13-8. doi:10.5681/apb.2015.002

Manin, A.N., Surov, A.O., Churakov, A. V, Perlovich, G.L., 2015. Crystal structures, thermal analysis, and dissolution behavior of new solid forms of the antiviral drug arbidol with dicarboxylic acids. Crystals 5, 650-669. doi:10.3390/cryst5040650

Mannhold, R. (Ed.), 2007. Molecular drug properties-measurement and prediction, Methods and Principles in Medicinal Chemistry. Wiley-VCH Verlag GmbH \& Co. KGaA, Weinheim, Germany. doi:10.1002/9783527621286

Matthews, B.W., 1975. Comparison of the predicted and observed secondary structure of T4 phage lysozyme. BBA - Protein Struct. 405, 442-451. doi:10.1016/0005-2795(75)90109-9

McNamara, D.P., Childs, S.L., Giordano, J., larriccio, A., Cassidy, J., Shet, M.S., Mannion, R., O'Donnell, E., Park, A., 2006. Use of a glutaric acid cocrystal to improve oral bioavailability of a low solubility API. Pharm. Res. 23, 1888-1897. doi:10.1007/s11095-006-9032-3

Miwa, Y., Hamamoto, H., Ishida, T., 2016. Lidocaine self-sacrificially improves the skin permeation of the acidic and poorly water-soluble drug etodolac via its transformation into an ionic liquid. Eur. J. Pharm. Biopharm. 102, 92-100. doi:10.1016/j.ejpb.2016.03.003 
Moradiya, H., Islam, M.T., Woollam, G.R., Slipper, I.J., Halsey, S., Snowden, M.J., Douroumis, D., 2014. Continuous cocrystallization for dissolution rate optimization of a poorly water-soluble drug. Cryst. Growth Des. 14, 189-198. doi:10.1021/cg401375a

Moradiya, H.G., Islam, M.T., Scoutaris, N., Halsey, S.A., Chowdhry, B.Z., Douroumis, D., 2016. Continuous manufacturing of high quality pharmaceutical cocrystals integrated with process analytical tools for in-line process control. Cryst. Growth Des. 16, 3425-3434. doi:10.1021/acs.cgd.6b00402

Mounika, P., Divya, G., Raj, S.V., Gowramma, A., 2016. Preparation and characterization of novel cocrystal forms of domperidone. Int. J. Med. Pharm. Res. 4, 179-184.

Mounika, P., Raj, S.V., Divya, G., Gowramma, A., Vijayamma, G., 2015. Preparation and characterization of novel co-crystal forms of fexofenadine. Int. J. Innov. Pharm. Res. 6, 458-463.

Nalte, Y., Nalte, Y.K., Arsul, V.A., Shep, S.G., Sunil Bothara, D.B., 2015. Solubility enhancement of nevirapine by cocrystallisation technique. J. Pharm. Res. 99, 556-561.

Nanjwade, V.K., Manvi, F.V., Ali, M.S., Nanjwade, B.K., 2011. Development and evaluation of prulifloxacin tablet. Int. J. DRUG Formul. Res. 2, 302-314.

Nijhawan, M., Sathesh Babu, P.R., Subrahmanyam, C., 2015. Cocrystals of irbesartan with hippuric acid. Indo Am. J. Pharm. Res. 5, 1323-1329.

O'Boyle, N.M., Banck, M., James, C.A., Morley, C., Vandermeersch, T., Hutchison, G.R., 2011. Open babel: An open chemical toolbox. J Cheminformatics 3. doi:10.1186/1758-2946-3-33

Patel, D.M., Shah, H.R., Patel, R.J., Patel, C.N., 2014. Preparation and characterization of lornoxicam Co-crystals. WORLD J. Pharm. Pharm. Sci. 3, 713-732.

Paun, J.S., Chapla, V.K., Raval, M.K., Tank, H.M., 2013. Improvement of physicochemical properties of tinidazole cocrystals: An influence of additives. Indo Am. J. Pharm. Res. 3, 3680-3688.

Pestieau, A., Evrard, B., 2017. In vitro biphasic dissolution tests and their suitability for establishing in vitro-in vivo correlations: A historical review. Eur. J. Pharm. Sci. 102, 203-219. doi:10.1016/j.ejps.2017.03.019

Powers, D.M.W., 2011. Evaluation: From Precision, Recall and F-Measure To Roc, Informedness, Markedness \& Correlation. J. Mach. Learn. Technol. 2, 37-63. doi:10.1.1.214.9232

Prawiro, W.S., Murtini, G., Suprapti, T., Cartika, H., 2016. Enhancing dissolution rates of gliclazide via cocrystallization with nicotinamide. Asian J. Appl. Sci. 4, 899-905.

Przybyłek, M., Ziółkowska, D., Kobierski, M., Mroczyńska, K., Cysewski, P., 2016a. Utilization of oriented crystal growth for screening of aromatic carboxylic acids cocrystallization with urea. J. Cryst. Growth 433, 128-138. doi:10.1016/j.jcrysgro.2015.10.015

Przybyłek, M., Ziółkowska, D., Mroczyńska, K., Cysewski, P., 2017. Applicability of phenolic acids as effective enhancers of cocrystals solubility of methylxanthines. Cryst. Growth Des. acs.cgd.7b00121. doi:10.1021/acs.cgd.7b00121

Przybyłek, M., Ziółkowska, D., Mroczyńska, K., Cysewski, P., 2016b. Propensity of salicylamide and ethenzamide cocrystallization with aromatic carboxylic acids. Eur. J. Pharm. Sci. doi:10.1016/j.ejps.2016.02.010

Punita, Y., Manoj Kumar, M., Singh Shekhar, G., Raj Keshwar, P., Manoj Kumar Mishra, C., 2016. CoCrystal Formation Of Cilnidipine With Urea And Benzoic Acid: An Efficient Approach To Enhance The Solubilty And Dissolution Rate. J. Med. Pharm. Allied Sci. 1-9.

Rajbhar, P., Gautam, S.S., Prasad, R.K., Patel, A.K., Sahu, A.K., 2016a. Co-Crystals formation of clarithromycin with urea : An efficient approach to enhance the solubility and dissolution rate. Am. J. Adv. Drug Deliv. 4, 12-20.

Rajbhar, P., Sahu, A.K., Gautam, S.S., Prasad, R.K., Singh, V., 2016b. Formulation and evaluation of clarithromycin co-crystals tablets dosage forms to enhance the bioavailability. Pharma Innov. J. 5, 5-13.

Remenar, J.F., Morissette, S.L., Peterson, M.L., Moulton, B., MacPhee, J.M., Guzmán, H.R., Almarsson, Ö., 2003. Crystal engineering of novel cocrystals of a triazole drug with 1,4-dicarboxylic acids. J. Am. Chem. Soc. 125, 8456-8457. doi:10.1021/ja035776p

Remenar, J.F., Peterson, M.L., Stephens, P.W., Zhang, Z., Zimenkov, Y., Hickey, M.B., 2007. Celecoxib:nicotinamide dissociation: Using excipients to capture the cocrystal's potential. Mol. 
Pharm. 4, 386-400. doi:10.1021/mp0700108

Renkoğlu, P., Çelebier, M., Arıca-Yegin, B., 2015. HPLC determination of olanzapine and carbamazepine in their nicotinamide cocrystals and investigation of the dissolution profiles of cocrystal tablet formulations. Pharm. Dev. Technol. 20, 380-384. doi:10.3109/10837450.2014.882937

Ross, S.A., Lamprou, D.A., Douroumis, D., Markl, D., Schrank, S., Jones, I., Cruise, P., Murb, R., Koscher, G., Roblegg, E., Khinast, J., 2016. Engineering and manufacturing of pharmaceutical cocrystals: a review of solvent-free manufacturing technologies. Chem. Commun. 52, 8772-8786. doi:10.1039/C6CC01289B

Sanphui, P., Bolla, G., Nangia, A., Chernyshev, V., 2014. Acemetacin cocrystals and salts: Structure solution from powder X-ray data and form selection of the piperazine salt. IUCrJ 1, 136-150. doi:10.1107/S2052252514004229

Sanphui, P., Goud, N.R., Khandavilli, U.B.R., Nangia, A., 2011. Fast dissolving curcumin cocrystals. Cryst. Growth Des. 11, 4135-4145. doi:10.1021/cg200704s

Sareen, S., Mathew, G., Joseph, L., 2012. Improvement in solubility of poor water-soluble drugs by solid dispersion. Int. J. Pharm. Investig. 2, 12-7. doi:10.4103/2230-973X.96921

Sateesh Babu, J.M., Sevukarajan, M., Thamizhvanan, K., Naveenkumar, B., Sreekanth Reddy, B., Vivekananda, U., Shyamkumar, V., 2013. Evaluation of physiochemical and anti-tubercular activity of co-crystal of isoniazid with methyl paraben. Int. J. Innov. Drug Discov. 3, 10-27.

Savjani, K.T., Gajjar, A.K., Savjani, J.K., 2012. Drug solubility: importance and enhancement techniques. ISRN Pharm. 2012, 195727. doi:10.5402/2012/195727

Schultheiss, N., Newman, A., 2009. Pharmaceutical cocrystals and their physicochemical properties. Cryst. Growth Des. 9, 2950-2967. doi:10.1021/cg900129f

Sekhon, B., 2012. Nutraceutical cocrystals: An overview. RGUHS J. Pharm. Sci 2, 16-25. doi:10.5530/rjps.2012.2.3

Serajuddin, A.T., 1999. Solid dispersion of poorly water-soluble drugs: early promises, subsequent problems, and recent breakthroughs. J. Pharm. Sci. 88, 1058-66.

Serrano, D.R., Persoons, T., D’Arcy, D.M., Galiana, C., Dea-Ayuela, M.A., Healy, A.M., 2016. Modelling and shadowgraph imaging of cocrystal dissolution and assessment of in vitro antimicrobial activity for sulfadimidine/4-aminosalicylic acid cocrystals. Eur. J. Pharm. Sci. 89, 125-136. doi:10.1016/j.ejps.2016.04.030

Shah, K., Borhade, S., Londhe, V., 2004. Utilization of co-crystallization for solubility enhancement of a poorly soluble antiretroviral drug-ritonavir. Int. J. Pharm. Pharm. Sci. 6, 556-558. doi:ISSN0975-1491

Shayanfar, A., Asadpour-Zeynali, K., Jouyban, A., 2013. Solubility and dissolution rate of a carbamazepine-cinnamic acid cocrystal. J. Mol. Liq. 187, 171-176. doi:10.1016/j.molliq.2013.06.015

Shewale, S., Shete, A.S., Doijad, R.C., Kadam, S.S., Patil, V.A., Yadav, A. V, 2015. Formulation and Solid State Characterization of Nicotinamide-based Co-crystals of Fenofibrate. Indian J. Pharm. Sci. 77, 328-34.

Shi, X., Gao, J., Liu, Z., Zhang, J., Gao, Y., 2013. Enhanced dissolution of famotidine by cocrystal formation with tartaric acid and maleic acid. J. China Pharm. Univ. 124-129.

Shiraki, K., Takata, N., Takano, R., Hayashi, Y., Terada, K., 2008. Dissolution improvement and the mechanism of the improvement from cocrystallization of poorly water-soluble compounds. Pharm. Res. 25, 2581-2592. doi:10.1007/s11095-008-9676-2

Shohin, I.E., Grebenkin, D.Y., Malashenko, E.A., Stanishevskii, Y.M., Ramenskaya, G. V., 2016. A brief review of the FDA dissolution methods database. Dissolution Technol. doi:10.14227/DT230316P6

Sinha, A.S., Maguire, A.R., Lawrence, S.E., 2015. Cocrystallization of nutraceuticals. Cryst. Growth Des. 15, 984-1009. doi:10.1021/cg501009c

Sironi, D., Rosenberg, J., Bauer-Brandl, A., Brandl, M., 2017. Dynamic dissolution-/permeation-testing of nano- and microparticle formulations of fenofibrate. Eur. J. Pharm. Sci. 96, 20-27. doi:10.1016/j.ejps.2016.09.001 
Siswandi, S., Rusdiana, T., Levita, J., 2015. Virtual screening of co-formers for ketoprofen cocrystallization and the molecular properties of the co-crystal. J. Appl. Pharm. Sci. 5, 78-82. doi:10.7324/JAPS.2015.50613

Six, K., Verreck, G., Peeters, J., Brewster, M., Van Den Mooter, G., 2004. Increased physical stability and improved dissolution properties of itraconazole, a class II drug, by solid dispersions that combine fast- and slow-dissolving polymers. J. Pharm. Sci. 93, 124-131. doi:10.1002/jps.10522

Smith, A.J., Kavuru, P., Arora, K.K., Kesani, S., Tan, J., Zaworotko, M.J., Shytle, R.D., 2013. Crystal engineering of green tea epigallocatechin-3-gallate (EGCg) cocrystals and pharmacokinetic modulation in rats. Mol. Pharm. 10, 2948-2961. doi:10.1021/mp4000794

Smith, A.J., Kavuru, P., Wojtas, L., Zaworotko, M.J., Shytle, R.D., 2011. Cocrystals of quercetin with improved solubility and oral bioavailability. Mol. Pharm. 8, 1867-1876. doi:10.1021/mp200209j

Sohrab, M., Mahapatra, S.P., Tiwari, S., 2015. Enhancement of dissolution rate of aceclofenac by formation of aceclofenac-nicotinic acid cocrystal using water soluble polymers. Indo Glob. J. Pharm. Sci. 5, 154-170.

Sruti, J., Niranjan Patra, C., Swain, S., Panigrahi, K.C., Patro, A.P., Beg, S., Dinda, S.C., Rao, M.E.B., 2013. Improvement in the dissolution rate and tableting properties of cefuroxime axetil by melt-granulated dispersion and surface adsorption. Acta Pharm. Sin. B 3, 113-122. doi:10.1016/j.apsb.2013.01.001

Sugandha, K., Kaity, S., Mukherjee, S., Isaac, J., Ghosh, A., 2014. Solubility enhancement of ezetimibe by a cocrystal engineering technique. Cryst. Growth Des. 14, 4475-4486. doi:10.1021/cg500560w

Szegezdi, J., Csizmadia, F., 2007. A method for calculating the pKa values of small and large molecules. Am. Chem. Soc. Spring Meet.

Takata, N., Shiraki, K., Takano, R., Hayashi, Y., Terada, K., 2008. Cocrystal screening of stanolone and mestanolone using slurry crystallization. Cryst. Growth Des. 8, 3032-3037. doi:10.1021/cg800156k

Thiry, J., Broze, G., Pestieau, A., Tatton, A.S., Baumans, F., Damblon, C., Krier, F., Evrard, B., 2016. Investigation of a suitable in vitro dissolution test for itraconazole-based solid dispersions. Eur. J. Pharm. Sci. 85, 94-105. doi:10.1016/j.ejps.2016.02.002

Thiry, J., Kok, M.G.M., Collard, L., Frère, A., Krier, F., Fillet, M., Evrard, B., 2017a. Bioavailability enhancement of itraconazole-based solid dispersions produced by hot melt extrusion in the framework of the Three Rs rule. Eur. J. Pharm. Sci. 99, 1-8. doi:10.1016/j.ejps.2016.12.001

Thiry, J., Krier, F., Ratwatte, S., Thomassin, J.-M., Jerome, C., Evrard, B., 2017b. Hot-melt extrusion as a continuous manufacturing process to form ternary cyclodextrin inclusion complexes. Eur. J. Pharm. Sci. 96, 590-597. doi:10.1016/j.ejps.2016.09.032

Todeschini, R., Consonni, V., 2010. Molecular Descriptors for Chemoinformatics, Recent Advances in QSAR Studies. doi:10.1002/9783527628766

Tröbs, L., Emmerling, F., 2014. Mechanochemical synthesis and characterisation of cocrystals and metal organic compounds. Faraday Discuss. 170, 109-119. doi:10.1039/C3FD00163F

TURBOMOLE-GmbH, 2015. TURBOMOLE V7.0, a development of University of Karlsruhe and Forschungszentrum Karlsruhe $\mathrm{GmbH}$.

Ullah, M., Hussain, I., Sun, C.C., 2016. The development of carbamazepine-succinic acid cocrystal tablet formulations with improved in vitro and in vivo performance. Drug Dev. Ind. Pharm. 42, 969-976. doi:10.3109/03639045.2015.1096281

Vihinen, M., 2012. How to evaluate performance of prediction methods? Measures and their interpretation in variation effect analysis. BMC Genomics 13, S2. doi:10.1186/1471-2164-13-S4S2

Vinesha, V., Sevukarajan, M., Rajalakshmi, R., Chowdary, G.T., Haritha, K., Vidyanikethan, S., Dt, C., Pradesh, A., 2013. Enhancement of solubility of tadalafil by cocrystal approach. Int. Res. J. Pharm. 4, 218-223. doi:10.7897/2230-8407.04444

Wang, I.-C., Lee, M.-J., Sim, S.-J., Kim, W.-S., Chun, N.-H., Choi, G.J., 2013. Anti-solvent cocrystallization of carbamazepine and saccharin. Int. J. Pharm. 450, 311-322. doi:10.1016/j.ijpharm.2013.04.012 
Xue, L., Bajorath, J., 2000. Molecular Descriptors in Chemoinformatics, Computational Combinatorial Chemistry, and Virtual Screening. Comb. Chem. High Throughput Screen. 3, 363-372. doi:10.2174/1386207003331454

Yadav, A., Shete, A., Dabke, A., Kulkarni, P., Sakhare, S., 2009. Co-crystals: A novel approach to modify physicochemical properties of active pharmaceutical ingredients. Indian J. Pharm. Sci. 71, 359. doi:10.4103/0250-474X.57283

Yamashita, H., Sun, C.C., 2016. Harvesting potential dissolution advantages of soluble cocrystals by depressing precipitation using the common coformer effect. Cryst. Growth Des. 16, 6719-6721. doi:10.1021/acs.cgd.6b01434

Yan, Y., Chen, J.-M., Geng, N., Lu, T.-B., 2012. Improving the solubility of agomelatine via cocrystals. Cryst. Growth Des. 12, 2226-2233. doi:10.1021/cg201423q

Yap, C.W., 2011. PaDEL-descriptor: An open source software to calculate molecular descriptors and fingerprints. J. Comput. Chem. 32, 1466-1474. doi:10.1002/jcc.21707

Zahid, S., 2014. Preparation of cocrystals of paracetamol with saccharin for obtaining improved dissolution profile (Thesis). Islamabad.

Žegarac, M., Leksic, E., Sket, P., Plavec, J., Devcic Bogdanovic, M., Bucar, D.-K., Dumic, M., Mestrovic, E., 2014. A sildenafil cocrystal based on acetylsalicylic acid exhibits an enhanced intrinsic dissolution rate. CrystEngComm 16, 32-35. doi:10.1039/c3ce42013b

Zhang, T., Yang, Y., Wang, H., Sun, F., Zhao, X., Jia, J., Liu, J., Guo, W., Cui, X., Gu, J., Zhu, G., 2013. Using dissolution and pharmacokinetics studies of crystal form to optimize the original iloperidone. Cryst. Growth Des. 13, 5261-5266. doi:10.1021/cg4010104

Zhang, T., Yang, Y., Zhao, X., Jia, J., Su, H., He, H., Gu, J., Zhu, G., 2014. Dissolution and pharmacokinetic properties of two paliperidone cocrystals with 4-hydroxybenzoic and 4aminobenzoic acid. CrystEngComm 16, 7667. doi:10.1039/C4CE00784K

Zhang, X., Tian, Y., Jia, J., Zhang, T., Zhu, G., 2016. Synthesis, characterization and dissolution of three pharmaceutical cocrystals based on deferiprone. J. Mol. Struct. 1108, 560-566. doi:10.1016/j.molstruc.2015.12.055 


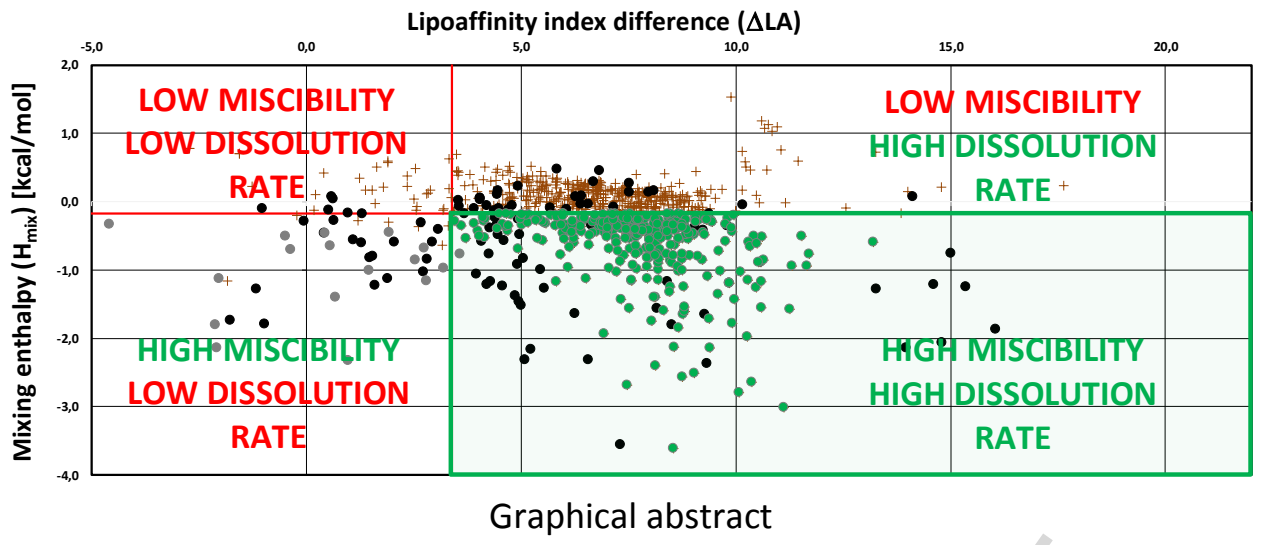

